\title{
Red blood cell parameters in antenatal nonsickling hemoglobinopathy screening
}

\author{
This article was published in the following Dove Press journal: \\ International Journal of Women's Health \\ 8 April 2015 \\ Number of times this article has been viewed
}

\author{
Gabriela Bencaiova \\ Kristina Dapoto \\ Roland Zimmermann \\ Alexander Krafft \\ Department of Obstetrics \\ and Gynecology, Institute of Obstetric \\ Research, University Hospital Zurich, \\ Zurich, Switzerland
}

Objective: To find a hematological parameter and the cut-off level for identification of nonsickling hemoglobinopathies in pregnant women.

Materials and methods: Venous blood samples of 849 women with singleton pregnancies were collected at the first visit. All women who met inclusion criteria were examined for nonsickling hemoglobinopathy. On the basis of the sensitivity and the specificity of different cut-off levels for hematological parameters, we calculated the optimal clinically practicable parameter for screening of nonsickling hemoglobinopathies in pregnant women.

Results: On the basis of the sensitivity and the specificity, the best screening parameters for the identification of nonsickling hemoglobinopathies among nonanemic pregnant women are mean corpuscular volume (MCV) with cut-off $\leq 80 \mathrm{fL}$ (Youden's index 91.2\%), mean corpuscular hemoglobin $(\mathrm{MCH})<27.5 \mathrm{pg}$ (Youden's index 90.7\%), and microcytosis (MRC) $\geq 3 \%$ (Youden's index $90.2 \%$ ). An analysis using receiver operating characteristic curves and the calculated Youden's index showed that $\mathrm{MCV} \leq 76 \mathrm{fL}, \mathrm{MCH} \leq 24 \mathrm{pg}$, or $\mathrm{MRC} \geq 10 \%$ are the best red blood cell indices for the screening of nonsickling hemoglobinopathy among anemic women with iron deficiency. Conclusion: Our results suggest targeted screening for nonsickling hemoglobinopathies in nonanemic pregnant women with $\mathrm{MCV} \leq 80 \mathrm{fL}, \mathrm{MCH} \leq 27.5 \mathrm{pg}$, or $\mathrm{MRC} \geq 3 \%$ and in anemic women with $\mathrm{MCV} \leq 76 \mathrm{fL}, \mathrm{MCH} \leq 24 \mathrm{pg}$, or $\mathrm{MRC} \geq 10 \%$.

Keywords: anemia, antenatal, hemoglobinopathy, pregnancy, screening, hemoglobin, hematological parameters

\section{Introduction}

Hemoglobinopathies are among the most common inherited disorders worldwide. ${ }^{1,2}$ Different policies for nonsickling hemoglobinopathies screening have been adapted in Europe. There are two strategies: one for high-prevalence areas, where all women are offered universal screening, and one for low-prevalence areas, where a more complex algorithm has been developed that is related to the red blood cell (RBC) indices results and the ethnic origin of women or her partner. ${ }^{3,4}$ Switzerland with the prevalence of $0.92 \%$ belongs to the low-prevalence areas. ${ }^{5}$

Antenatal nonsickling hemoglobinopathy screening in low-prevalence areas, the so-called targeted antenatal nonsickling hemoglobinopathies screening, means a twostep algorithm. The first step is a routine examination of RBC indices. However, to this day there are no generally used hematological parameters with a specific cut-off. Most laboratories use low mean corpuscular volume (MCV), low mean corpuscular hemoglobin $(\mathrm{MCH})$, or high microcytosis (MRC) as criteria for screening, but the specific cut-off under which further investigation is carried out varies widely. Older studies quote an $\mathrm{MCH}<27 \mathrm{pg}$ as a criterion, ${ }^{1,6}$ more recent ones quote $\mathrm{MCH}<26 \mathrm{pg}^{7}$ and $\mathrm{MCV}<78 \mathrm{fL},{ }^{1} \mathrm{MCV}<85 \mathrm{fL},{ }^{6}$ or $\mathrm{MCV}<80 \mathrm{fL} .{ }^{7}$ Using these parameters we
Correspondence: Gabriela Bencaiova Department of Obstetrics and Gynecology, University Hospital Zurich, Frauenklinikstrasse 10, $\mathrm{CH}-809$ |

Zurich, Switzerland

$\mathrm{Tel}+4 \mid 442553364$

Fax +4I 442554430

Email benca@bluewin.ch 
cannot identify women with normal red cell indices (silent thalassemia and silent hemoglobinopathy) as well as women with sickle cell disorders (sickle cell trait and sickle cell disease). In women with positive RBC indices, laboratory diagnosis should be conducted. ${ }^{8}$ Any woman with a hemoglobin variant whose partner has not been tested has been offered to have her partner tested for hemoglobinopathy.

As a result of the migration of people from countries with a high prevalence of hemoglobin disorders, laboratory diagnosis is of growing importance in North-West Europe. The aim of the early identification of women with nonsickling hemoglobinopathies is to optimize prenatal care. ${ }^{9}$ The purpose of this study is to determine a cut-off level of RBC indices for targeted nonsickling hemoglobinopathy screening in pregnant women.

\section{Materials and methods Study population}

A prospective cross-sectional study was carried out at the Department of Obstetrics and Gynecology, University Hospital Zurich. We examined 849 pregnant women with singleton pregnancies for their hematological status on the first visit to our antenatal clinic. The study was approved by the Human Research Ethics Committee at the Women's Hospital in Zurich. Written and informed consent was obtained before the examination for the identification of nonsickling hemoglobinopathy was conducted. Women who met inclusion criteria were tested for nonsickling hemoglobinopathy. Inclusion criteria for testing of nonsickling hemoglobinopathy were $\mathrm{MCH} \leq 28 \mathrm{pg}, \mathrm{MCV} \leq 81 \mathrm{fL}$, and $\mathrm{MRC} \geq 3 \%$ in nonanemic women and $\mathrm{MCH} \leq 26 \mathrm{pg}, \mathrm{MCV} \leq 77 \mathrm{fL}$, and $\mathrm{MRC} \geq 3 \%$ in anemic women. Women with sickle cell anemia were excluded from this analysis due to negative, ie, normal hematological parameters.

\section{Hematology assessment}

Hemoglobin (Hb), RBCs, hematocrit (HCT), MCV, and the percentage of microcytic and hypochromic erythrocytes (MRC and HRC) were measured using an ADVIA $^{\circledR}$ hematology analyzer system (Bayer Diagnostics, Leverkusen, Germany). $\mathrm{MCH}$ was automatically calculated from $\mathrm{Hb}$ and RBC. Serum ferritin was assessed by chemiluminescence immunoassay (ACS 190; Ciba/Corning Diagnostic Corp, Cleveland, OH, USA). C-reactive protein (CRP) was assessed in anemic women through immunoturbidimetry. A radioimmunoassay was performed to determine vitamin $B_{12}$ and folic acid. The hemoglobins were separated and processed by high-performance liquid chromatography (HPLC). Molecular analysis to identify the $\alpha$-thalassemia was conducted. Methods used are described elsewhere. ${ }^{2}$

\section{Study criteria}

According to current guidelines based on the recommendations of the Centers for Disease Control (USA), anemia in pregnancy is defined as an $\mathrm{Hb}$ value $<110 \mathrm{~g} / \mathrm{L}$ in both the first and third trimester and an $\mathrm{Hb}$ value $<105 \mathrm{~g} / \mathrm{L}$ in the second trimester. ${ }^{10} \mathrm{We}$ diagnosed iron depletion if the serum ferritin was $\leq 20 \mu \mathrm{g} / \mathrm{L} .^{11,12}$ In all anemic women, the ascertainment of ferritin, CRP, folic acid, and vitamin $\mathrm{B}_{12}$ were conducted. Iron deficiency anemia (IDA) was defined as $\mathrm{Hb}<110 \mathrm{~g} / \mathrm{L}$ and serum ferritin $\leq 20 \mu \mathrm{g} / \mathrm{L}$. Anemia of other etiology was defined as $\mathrm{Hb}<110 \mathrm{~g} / \mathrm{L}$ and ferritin $>20 \mu \mathrm{g} / \mathrm{L}$. This group included the following: vitamin $\mathrm{B}_{12}$ deficiency, folic acid deficiency, chronic inflammatory diseases (particularly HIVpositive women, hepatitis B, lupus erythematosus, etc), liver or kidney disease, etc.

\section{Study design}

We determined and compared the mean level of $\mathrm{Hb}, \mathrm{RBC}$, $\mathrm{HCT}, \mathrm{MCV}$, and $\mathrm{MCH}$ in all women; median of MRC and HRC in all women; and ferritin in women with inclusion criteria or with anemia. There were four groups of women: women with nonsickling hemoglobinopathy (group 1), women with IDA (group 2), women with anemia of other etiology (group 3), and nonanemic women (group 4). We determined sensitivity, specificity, positive predictive value (PPV), negative predictive value (NPV), and Youden's index of the following parameters in women with IDA: $\mathrm{MCH}$ with cut-off levels of $\leq 25 \mathrm{pg}, \leq 26 \mathrm{pg}, \leq 27$ $\mathrm{pg},<27.5 \mathrm{pg}$, and $\leq 28 \mathrm{pg} ; \mathrm{MCV}$ with cut-off levels of $\leq 75 \mathrm{fL}, \leq 76 \mathrm{fL}, \leq 77 \mathrm{fL}, \leq 78 \mathrm{fL}, \leq 79 \mathrm{fL}, \leq 80 \mathrm{fL}$, and $\leq 81 \mathrm{fL}$; andMRC with cut-offlevels of $\geq 3 \%, \geq 5 \%, \geq 10 \%$, and $\geq 15 \%$ in nonanemic women; and $\mathrm{MCH}$ with cut-off $\leq 23 \mathrm{pg}, \leq 24 \mathrm{pg}, \leq 25 \mathrm{pg}$, and $<26 \mathrm{pg}$; MCV with cut-off levels of $\leq 74 \mathrm{fL}, \leq 75 \mathrm{fL}, \leq 76 \mathrm{fL}$, and $\leq 77 \mathrm{fL}$; and MRC with cut-off levels of $\geq 3 \%, \geq 5 \%, \geq 10 \%$, and $\geq 15 \%$. Receiver operating characteristic curves were used to construct a graphic representation of the relation between sensitivity and specificity of the inclusion hematological parameters (MCV, MCH, and MRC).

\section{Statistical analysis}

Statistical analysis was performed with Intercooled Stata 8.2 for Windows (www.stata.com). The mean of hematological parameters ( $\mathrm{Hb}, \mathrm{RBC}, \mathrm{HCT}, \mathrm{MCV}$, and $\mathrm{MCH})$ and median of ferritin, HCR, and MRC and the standard deviation 
within the range were calculated for each group. Specificity, sensitivity, PPV, NPV, and Youden's index of different cut-off levels for $\mathrm{MCV}, \mathrm{MCH}$, and $\mathrm{MRC}$ in nonanemic pregnant women and women with IDA were calculated. The sensitivity was calculated as true positive/(true positive+false negative); the specificity was calculated as: true negative/ (true negative+false positive); PPV was calculated as: true positive/(true positive+false positive); NPV was calculated as: (true negative/true negative+false negative); Youden's index was calculated as (sensitivity+specificity)-100.

Receiver operating characteristic curves were used to construct a graphic representation of the relation between sensitivity and specificity of the three hematological parameters (MCV, $\mathrm{MCH}$, and MRC) with a highest sensitivity and specificity over all possible diagnostic cut-off values in nonanemic and anemic pregnant women.

\section{Results}

There were 849 women during enrolment and 829 women during the final analysis. Twenty women with $\mathrm{MCH} \leq 25 \mathrm{pg}$, $\mathrm{MCV} \leq 75 \mathrm{fL}$, and/or with anemia were excluded from the analysis due to loss to follow-up (9/20), poor compliance $(8 / 20)$, or negative hematological screening parameters in women with sickle cell anemia (3/20).

The hematological data of the four groups are shown in Table 1. The mean hemoglobin in the group with nonsickling hemoglobinopathies was $112 \pm 14 \mathrm{~g} / \mathrm{L}$. Only 12 women with nonsickling hemoglobinopathy suffered from anemia $(12 / 24 ; 50 \%)$ and 6 had concomitant iron deficiency $(6 / 24$; $25 \%$ ). However, the median of ferritin in this group was $50 \mu \mathrm{g} / \mathrm{L}$ and the median of hypochromic red cells for this group $(7.6 \%)$ was higher than that in the group with IDA $(2.8 \%)$. There was an increased erythrocyte count (mean
RBC $4.8 \pm 0.5 \times 10^{6} / \mu \mathrm{L}$ ) and increased MRC (median MRC $18.6 \%$ ) in this group of women. The mean gestational age on recruitment was $18 \pm 2$ weeks.

The overall prevalence of nonsickling hemoglobinopathies was 3.3\% (27/829). There were nine women with homozygous $\alpha$-thalassemia and six with heterozygous $\alpha$-thalassemia, one with homozygous $\beta$-thalassemia and six women with heterozygous $\beta$-thalassemia, two with hemoglobinopathy E, two women with heterozygous sickle cell anemia, and one with homozygous sickle cell anemia. Pregnant women with sickle cell anemia were excluded from the analysis due to negative hematological parameters. IDA was identified in 89 women $(89 / 829 ; 10.7 \%)$ and anemia of other etiology in $62(62 / 829 ; 7.5 \%)$. The median CRP in IDA was $2 \mathrm{mg} / \mathrm{L}(0-69)$ and that in women with other anemia $11 \mathrm{mg} / \mathrm{L}(0-206)$. There were 654 pregnant women without anemia and with the negative inclusion criteria (654/829; 78.9\%).

The sensivity, specificity, PPV, NPV, and Youden's index of different cut-off levels in nonanemic as well in anemic women for MCV are shown in Table 2, for MCH in Table 3 and for MRC in Table 4. On the basis of these results, the optimal cut-off level for identification of nonsickling hemoglobinopathies in nonanemic pregnant women as well in women with anemia for other reasons was $\mathrm{MCV} \leq 80 \mathrm{fL}$, $\mathrm{MCH} \leq 27.5 \mathrm{pg}$, or $\mathrm{MRC} \geq 3 \%$. A receiver operating characteristic curve for nonanemic women is shown in Figure 1. The combination of two parameters does not improve the sensitivity and specificity.

By using $\mathrm{MCH} \leq 25 \mathrm{pg}$, we correctly identified $79.2 \%$ of women with nonsickling hemoglobinopathies, and by using $\mathrm{MCV} \leq 75 \mathrm{fL}$ only $66.7 \%$. An analysis using receiver operating characteristic curves and the calculated Youden's index

Table I The hematological data of the four groups - group I: nonsickling hemoglobinopathies (24); group 2: IDA (89); group 3: anemia of other etiology (62); group 4: normal (654)

\begin{tabular}{|c|c|c|c|c|c|c|c|c|}
\hline & \multicolumn{2}{|l|}{ Group I } & \multicolumn{2}{|l|}{ Group 2} & \multicolumn{2}{|l|}{ Group 3} & \multicolumn{2}{|l|}{ Group 4} \\
\hline & Mean (SD) & Range & Mean (SD) & Range & Mean (SD) & Range & Mean (SD) & Range \\
\hline $\mathrm{Hb}(\mathrm{g} / \mathrm{L})$ & II2 (I4.2) & $75-147$ & I0I (7.0) & $74-109$ & $104(6.3)$ & $83-109$ & $125(8.7)$ & $110-158$ \\
\hline $\mathrm{RBC}\left(\times 10^{6} / \mu \mathrm{L}\right)$ & $4.8(0.5)$ & $3.7-5.9$ & $3.6(0.3)$ & $3.0-4.5$ & $3.5(0.3)$ & $2.7-4.6$ & 4.I (0.4) & $2.8-7.1$ \\
\hline HCT (\%) & $33.9(4.1)$ & $24-43$ & $29.8(2.0)$ & $23-34$ & $29.9(1.7)$ & $25-32$ & $35.9(2.6)$ & $30-49$ \\
\hline $\mathrm{MCV}(\mathrm{fL})$ & $71(6.0)$ & $59-82$ & $83(7.4)$ & $66-98$ & 87 (5.9) & $69-109$ & $87(4.5)$ & $69-105$ \\
\hline \multirow[t]{2}{*}{$\mathrm{MCH}(\mathrm{pg})$} & $24(2.3)$ & $20-28$ & $28(3.0)$ & $21-35$ & $30(2.5)$ & $22-38$ & 31 (I.9) & $21-37$ \\
\hline & Median & Range & Median & Range & Median & Range & Median & Range \\
\hline MRC (\%) & 18.6 & $2.5-59$ & 1.8 & $0.1-35$ & 0.9 & $0.1-27$ & 0.6 & $0-10$ \\
\hline HRC (\%) & 7.6 & $0.3-15$ & 2.8 & $0.1-36$ & 0.6 & $0.1-16$ & 0.2 & $0-11$ \\
\hline Ferritin $(\mu g / L)$ & 50 & $5-533$ & 8 & $2-20$ & 46 & $21-192$ & & \\
\hline
\end{tabular}

Note: Parameter was not determined in this group.

Abbreviations: $\mathrm{Hb}$, hemoglobin; $\mathrm{HCT}$, hematocrit; IDA, iron deficiency anemia; $\mathrm{MCH}$, mean corpuscular hemoglobin; MCV, mean corpuscular volume; MRC, microcytosis; HRC, hypochromic erythrocytes; RBC, red blood cell; SD, standard deviation. 
Table 2 Specificity, sensitivity, PPV, NPV, and Youden's index of different cut-off levels for MCV in (a) nonanemic pregnant women and (b) women with IDA

\begin{tabular}{|c|c|c|c|c|c|}
\hline $\begin{array}{l}\text { MCV, } \\
\text { fL }\end{array}$ & Sensitivity & Specificity & PPV & NPV & $\begin{array}{l}\text { Youden's } \\
\text { index, \% }\end{array}$ \\
\hline \multicolumn{6}{|l|}{ (a) } \\
\hline$\leq 75$ & 66.7 & 99.2 & 76.2 & 98.8 & 65.9 \\
\hline$\leq 76$ & 75.0 & 99.1 & 78.3 & 99.1 & 74.1 \\
\hline$\leq 77$ & 75.0 & 98.6 & 66.7 & 99.1 & 73.6 \\
\hline$\leq 78$ & 87.5 & 98.0 & 61.8 & 99.5 & 85.5 \\
\hline$\leq 79$ & 91.7 & 97.1 & 53.7 & 99.7 & 88.8 \\
\hline$\leq 80$ & 95.8 & 95.4 & 43.4 & 99.8 & 91.2 \\
\hline$\leq 81$ & 95.8 & 93.9 & 36.5 & 99.8 & 89.7 \\
\hline \multicolumn{6}{|l|}{ (b) } \\
\hline$\leq 74$ & 66.7 & 86.5 & 57.1 & 90.6 & 76.6 \\
\hline$\leq 75$ & 66.7 & 82.0 & 50.0 & 90.1 & 74.4 \\
\hline$\leq 76$ & 75.0 & 78.6 & 48.7 & 92.1 & 76.8 \\
\hline$\leq 77$ & 75.0 & 75.3 & 45.0 & 91.8 & 75.2 \\
\hline
\end{tabular}

Note: Results expressed in \%.

Abbreviations: IDA, iron deficiency anemia; MCV, mean corpuscular volume; NPV, negative predictive value; PPV, positive predictive value.

showed that $\mathrm{MCV} \leq 76 \mathrm{fL}, \mathrm{MCH} \leq 24 \mathrm{pg}$, or $\mathrm{MRC} \geq 10 \%$ are the optimal cut-off levels for differentiation nonsickling hemoglobinopathies among women with concomitant IDA. $\mathrm{MCH} \leq 24 \mathrm{pg}$ had a sensitivity of $75 \%$ and a specificity of 91\% (Youden's index 83.0\%; Table 3), MCV $\leq 76 \mathrm{fL}$ had a sensitivity of $75.0 \%$ and a specificity of $78.6 \%$ (Youden's index 76.8\%; Table 2), and MRC $\geq 10 \%$ had a sensitivity of $70.8 \%$ and a specificity of $84.3 \%$ (Youden's index $77.6 \%$; Table 4). On the basis of our results, the algorithm of targeted antenatal nonsickling hemoglobinopathy screening is shown in Figure 2.

Table 3 Specificity, sensitivity, PPV, NPV, and Youden's index of different cut-off levels for $\mathrm{MCH}$ in (a) nonanemic pregnant women and (b) women with IDA

\begin{tabular}{|c|c|c|c|c|c|}
\hline MCH, pg & Sensitivity & Specificity & PPV & NPV & $\begin{array}{l}\text { Youden's } \\
\text { index, \% }\end{array}$ \\
\hline \multicolumn{6}{|l|}{ (a) } \\
\hline$\leq 25$ & 79.2 & 99.2 & 79.2 & 99.2 & 78.4 \\
\hline$\leq 26$ & 79.1 & 97.9 & 57.6 & 99.2 & 77.0 \\
\hline$\leq 27$ & 87.5 & 96.3 & 46.7 & 99.5 & 83.8 \\
\hline$\leq 27.5$ & 95.8 & 94.9 & 41.1 & 99.8 & 90.7 \\
\hline$\leq 28$ & 95.8 & 91.3 & 28.8 & 99.8 & 87.1 \\
\hline \multicolumn{6}{|l|}{ (b) } \\
\hline$\leq 23$ & 54.2 & 95.5 & 76.5 & 88.5 & 74.9 \\
\hline$\leq 24$ & 75.0 & 91.0 & 69.2 & 93.1 & 83.0 \\
\hline$\leq 25$ & 79.2 & 83.2 & 55.9 & 93.7 & 81.2 \\
\hline$\leq 26$ & 79.2 & 71.9 & 43.2 & 92.8 & 75.6 \\
\hline
\end{tabular}

Note: Results expressed in \%.

Abbreviations: IDA, iron deficiency anemia; $\mathrm{MCH}$, mean corpuscular hemoglobin; NPV, negative predictive value; PPV, positive predictive value.
Table 4 Specificity, sensitivity, PPV, NPV, and Youden's index of different cut-off levels for MRC in (a) nonanemic pregnant women and (b) women with IDA

\begin{tabular}{clllll}
\hline MRC, \% & Sensitivity & Specificity & PPV & NPV & $\begin{array}{c}\text { Youden's } \\
\text { index, \% }\end{array}$ \\
\hline $\begin{array}{lllll}\text { (a) } \\
\geq 3\end{array}$ & 95.8 & 94.4 & 40.4 & 99.8 & 90.2 \\
$\geq 5$ & 75.0 & 98.1 & 60.0 & 99.1 & 73.1 \\
$\geq 10$ & 70.8 & 99.5 & 85.0 & 99.0 & 70.3 \\
$\geq 15$ & 58.3 & 99.8 & 93.3 & 98.5 & 58.1 \\
(b) & & & & & \\
$\geq 3$ & 95.8 & 58.4 & 38.3 & 98.1 & 77.1 \\
$\geq 5$ & 75.0 & 73.0 & 42.9 & 91.6 & 74.0 \\
$\geq 10$ & 70.8 & 84.3 & 54.9 & 91.5 & 77.6 \\
$\geq 15$ & 58.3 & 89.9 & 60.9 & 88.9 & 74.1 \\
\hline
\end{tabular}

Note: Results expressed in \%.

Abbreviations: IDA, iron deficiency anemia; MRC, microcytosis; NPV, negative predictive value; PPV, positive predictive value.

\section{Discussion}

The present study evaluates the sensitivity and the specificity of $\mathrm{RBC}$ parameters with different cut-off levels for targeted antenatal nonsickling hemoglobinopathy screening. On the basis of our results, the optimal cut-off level in nonanemic women and in women with anemia for other reasons are $\mathrm{MCV} \leq 80 \mathrm{fL}$, $\mathrm{MCH} \leq 27.5 \mathrm{pg}$, or $\mathrm{MRC} \geq 3 \%$; and in women with IDA, the values are $\mathrm{MCV} \leq 76 \mathrm{fL}, \mathrm{MCH} \leq 24 \mathrm{pg}$, or $\mathrm{MRC} \geq 10 \%$. The combination of two parameters does not improve the sensitivity and specificity. The sensitivity and specificity vary depending on the type of nonsickling hemoglobinopathy. Hence, MCV $\leq 75 \mathrm{fL}$ was indicative in $100 \%$ of women with $\beta$-thalassemia, whereas it was indicative only in $53.3 \%$ of women with $\alpha$-thalassemia. On the other hand, using lower cut-off levels, ie, $\mathrm{MCV} \leq 77 \mathrm{fL}$ or $\mathrm{MCH} \leq 26 \mathrm{pg}$, the explicit decrease of the sensitivity was assessed among nonanemic women.

The prevalence of nonsickling hemoglobinopathies among all women was 3.3\% (27/829). Only one study described the prevalence of nonsickling hemoglobinopathy in Switzerland. ${ }^{5}$ In contrast to this study, a three-fold higher prevalence was determined in our study. The reason for this increase is a change in the population due to migration; namely, an increased number of refugees and asylum seekers from former Yugoslavia and other developing countries. Apart from Luxembourg and Liechtenstein, Switzerland with $20.6 \%$ has the highest rate of migrants among the general population in Western Europe. ${ }^{12}$

To our surprise, half of the pregnant women with nonsickling hemoglobinopathies were nonanemic. Mild anemia with $\mathrm{Hb}>100 \mathrm{~g} / \mathrm{L}$ was observed in only $16.7 \%(1 / 6)$ of women with heterozygous $\alpha$-thalassemia, in $66.6 \%(6 / 9)$ of women 


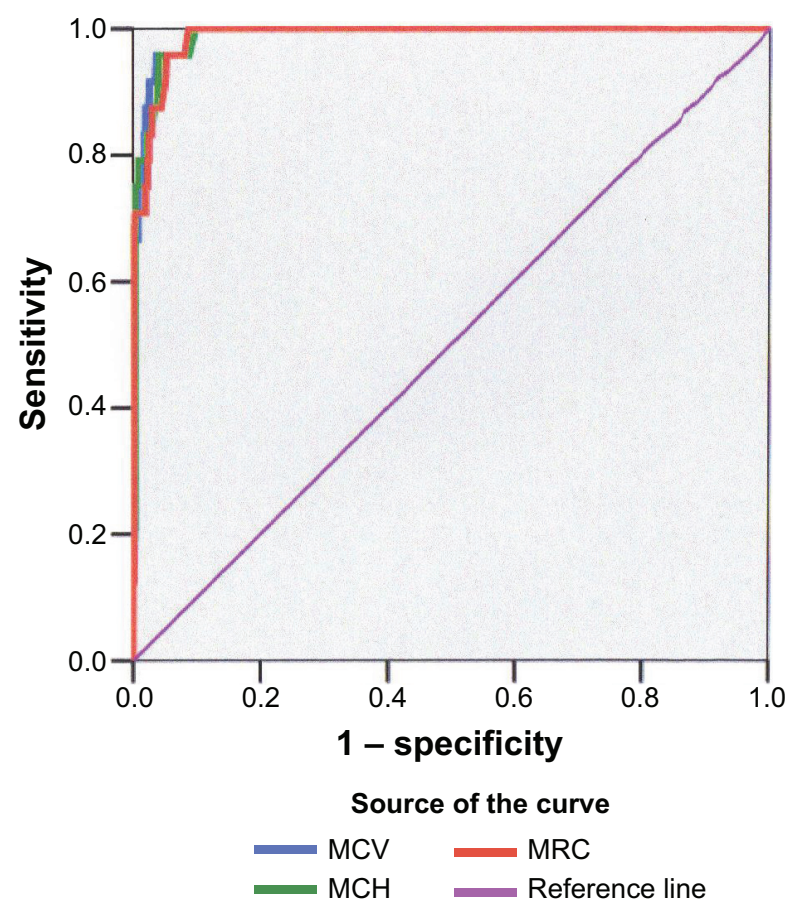

Figure I Receiver operating characteristic curves of the three parameters for nonsickling hemoglobinopathy screening among nonanemic women.

Abbreviations: $\mathrm{MCH}$, mean corpuscular hemoglobin; $\mathrm{MCV}$, mean corpuscular volume; MRC, microcytosis.

with homozygous $\alpha$-thalassemia, and in $50 \%$ (3/6) of women with heterozygous $\beta$-thalassemia. That means that if we only screen anemic women in pregnancy, we miss a huge group of women who are at risk. Therefore, laboratory diagnosis should be performed in all women with positive $\mathrm{RBC}$ indices regardless of hemoglobin and iron status. Using these parameters we can identify a huge group of individuals who are carriers of $\alpha$ - or $\beta$-thalassemia. However, as some women have normal red cell indices, it is impossible to detect all women by screening on the basis of the full blood count alone. Because of false positivity of red cell indices due to iron deficiency, ${ }^{13-15}$ different cut-off levels are used in nonanemic and anemic women. In women with IDA and MCV $\leq 76 \mathrm{fL}, \mathrm{MCH} \leq 24 \mathrm{pg}$, or MRC $\geq 10 \%$, the laboratory analysis is recommended because iron deficiency potentially masks hemoglobinopathy. It might be useful to correct iron deficiency before performing HPLC or molecular diagnostics.

The limitation of our study is the lack of HPLC and molecular analysis in all women. However, in a country with a low prevalence of hemoglobin disorders, conducting universal screening would not be cost effective. The choice of the screening method is based on cost-effectiveness, and it has been demonstrated that at a prevalence of at least 16 sickle cell traits/1,000 there is no significant cost difference between universal and targeted screening programs. Therefore, targeted antenatal screening is recommended in Switzerland. However, as a result of our study, we presume the difference of the prevalence between prevalence in the country and in the big city. Zurich with the prevalence of $3.3 \%$ belongs to the high-prevalence areas. Therefore, like in Belgium, the universal antenatal screening should be limited to the big cities in the future. The second debatable point is the cut-off level of serum ferritin. In the literature, the cut-off level of serum ferritin varies between $10 \mu \mathrm{g} / \mathrm{L}$ and $20 \mu \mathrm{g} / \mathrm{L} .{ }^{11,12}$ Because we saw high intraindividual variations between $10 \mu \mathrm{g} / \mathrm{L}$ and $20 \mu \mathrm{g} / \mathrm{L}$, we chose ferritin $\leq 20 \mu \mathrm{g} / \mathrm{L}$ as the cut-off level.

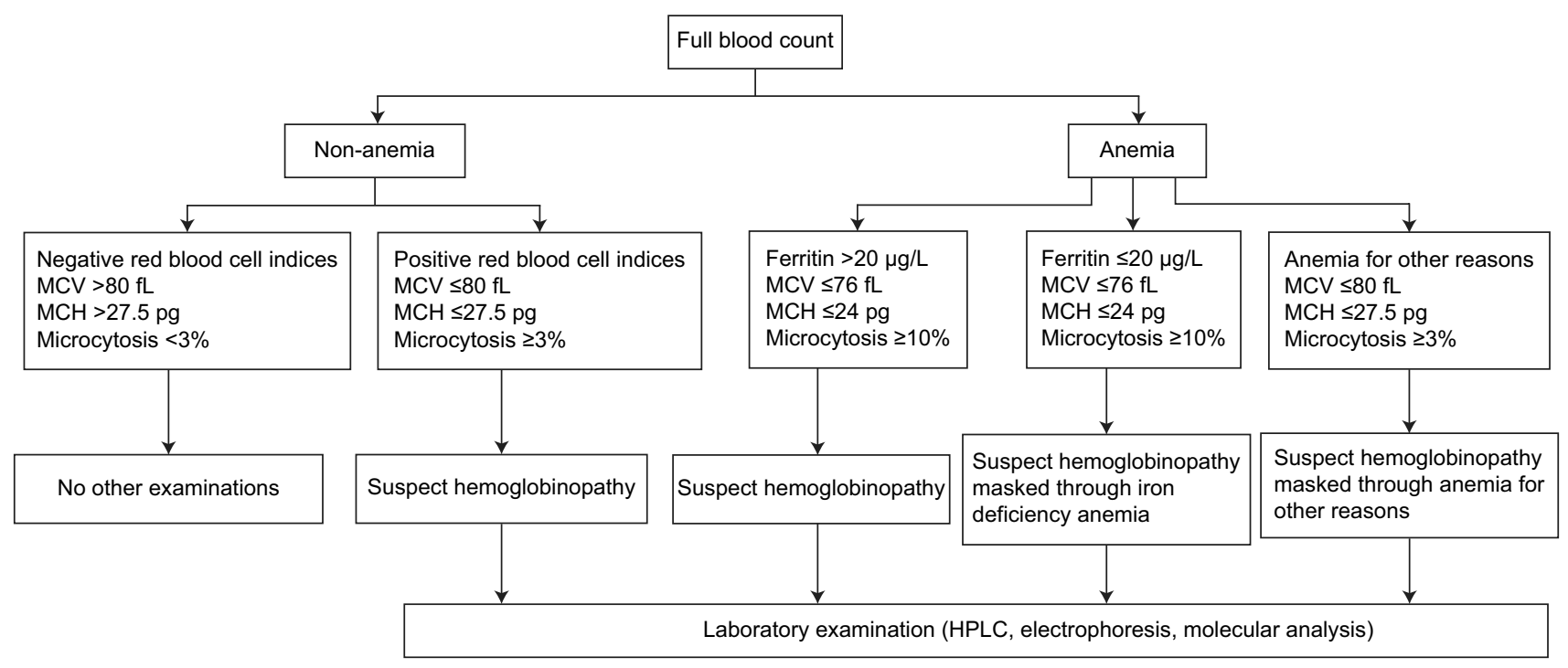

Figure 2 The algorithm of targeted antenatal nonsickling hemoglobinopathy screening.

Abbreviations: HPLC, high-performance liquid chromatography; $\mathrm{MCH}$, mean corpuscular hemoglobin; MCV, mean corpuscular volume. 
The impact of antenatal screening programs is generally assessed by the uptake of prenatal diagnosis, optimal management, care, and termination of affected pregnancies. ${ }^{16-18}$ Therefore, four European countries with high prevalence of hemoglobinopathy have adopted a universal neonatal screening program financed by the authorities in public health (England, France, Belgium, and recently, the Netherlands) and one country (Portugal) has adopted an antenatal universal screening. ${ }^{5,19}$ Since the discovery of cell-free fetal DNA in maternal plasma, the noninvasive prenatal assessment of hemoglobinopathies has been achieved. ${ }^{20}$

\section{Acknowledgment}

We thank Professor Rousson of the Department of Biostatistics, University of Zurich, for making statistical analysis with the receiver operating characteristic curves.

\section{Disclosure}

The authors report no conflicts of interest in this work.

\section{References}

1. Cao A, Rosatelli MC. Screening and prenatal diagnosis of the haemoglobinopathies. Baillieres Clin Haematol. 1993;6:263-286.

2. Krafft A, Breymann C. Haemoglobinopathy in pregnancy: diagnosis and treatment. Curr Med Chem. 2004;11:2903-2909.

3. Old JM. Screening and genetic diagnosis of haemoglobinopathies. Scand J Clin Lab Invest. 2007;67:71-86.

4. Greengross P, Hickman M, Gill M, Dugan B, Davies SC. Outcomes of universal antenatal screening for haemoglobinopathies. J Med Screen. 1999;6:3-10.

5. Bain BJ. Neonatal/newborn haemoglobinopathy screening in Europe and Africa. J Clin Pathol. 2009;62:53-56.

6. Rogers M, Phelan L, Bain B. Screening criteria for $\beta$ thalassaemia trait in pregnant women. J Clin Pathol. 1995;48:1054-1056.
7. Law HY, Chee MK, Tan GP, Ng IS. The simultaneous presence of $\alpha$ - and $\beta$-thalassaemia alleles: a pitfall of thalassaemia screening. Community Genet. 2003;6:14-21.

8. Working Party of the General Haematology Task Force of the British Committee for Standards in Haematology. The laboratory diagnosis of haemoglobinopathies. Br J Haematol. 1998;101:783-792.

9. Wanapirak C, Tongsong T, Sirivatanapa P, Sanguansermsri T, Sekararithi R, Tuggapichitti A. Prenatal strategies for reducing severe thalassemia in pregnancy. Int J Gynaecol Obstet. 1998;60:239-244.

10. Centers for Disease Control (CDC). CDC criteria for anemia in children and childbearing-aged women. MMWR Morb Mortal Wkly Rep. 1989;38: 400-404.

11. Thinkhamrop J, Apiwantanakul S, Lumbiganon P, Buppasiri P. Iron status in anemic women. J Obstet Gynaecol Res. 2003;29:160-163.

12. Institute of Medicine. Iron Deficiency Anemia: Recommended Guidelines for the Prevention, Detection, and Management among U.S. Children and Women of Childbearing Age. Washington, DC: National Academy Press; 1993.

13. Swiss Federal Statistical Office. Demographic portrait of Switzerland 2005 Edition. Available from: http://www.bfs.admin.ch/bfs/portal/de/ index/themen/01/22/publ/portrait_dem/liste.html?publicationID=1998. Accessed September 19, 2005.

14. Demir A, Yarali N, Fisgin T, Duru F, Kara A. Most reliable indices in differentiation between thalassemia trait and iron deficiency anemia. Pediatr Int. 2002;44:612-626.

15. Eldibany MM, Totonchi KF, Joseph NJ, Rhone D. Usefulness of certain red blood cell indices in diagnosing and differentiating thalassemia trait from iron-deficiency anemia. Am J Clin Pathol. 1999;111:676-682.

16. Bencaiova G, Burkhardt T, Krafft A, Zimmermann R. Screening for $\beta$-thalassaemia trait in anaemic pregnant women. Gynecol Obstet Invest. 2006;62:20-27.

17. Modell B, Ward RH, Fairweather DV. Effect of introducing antenatal diagnosis on reproductive behaviour of families at risk of thalassaemia major. BMJ. 1980;280:1347-1350.

18. Rowley PT. Prenatal diagnosis for sickle cell disease. A survey of the United States and Canada. Ann N Y Acad Sci. 1989;565:48-52.

19. Gulbis B, Cotton F, Ferster A, et al. Neonatal haemoglobinopathy screening in Belgium. J Clin Pathol. 2009;62:49-52.

20. Lun F, Tsui N, Chan A, et al. Noninvasive prenatal diagnosis of monogenic diseases by digital size selection and relation dosage on DNA in maternal plasma. Proc Natl Acad Sci U S A. 2008;105:19920-19925.
International Journal of Women's Health

\section{Publish your work in this journal}

The International Journal of Women's Health is an international, peerreviewed open-access journal publishing original research, reports, editorials, reviews and commentaries on all aspects of women's healthcare including gynecology, obstetrics, and breast cancer. The manuscript management system is completely online and includes

\section{Dovepress}

a very quick and fair peer-review system, which is all easy to use. Visit http://www.dovepress.com/testimonials.php to read real quotes from published authors. 